"Otsekui maailm klaasseina taga..." Allikainest Aleksander Aspeli hiliseluloole

Mart Orav

Kirjandusteadlane, kriitik ja tõlkija Aleksander Aspel (1908 Mustvee - 1975 lowa City) lõpetas Tartu ülikooli romaani filoloogina ning ta suunati 1938. aastal stipendiaadina Prantsusmaale valmistuma õppejõuametiks Tartus. Pärast Eesti okupeerimist Nõukogude Liidu poolt 1940. aastal ning sellele järgnenud Saksa okupatsiooni ajal ei naasnud ta kodumaale ning jäi Pariisi, kus tegutses põhiliselt eesti keele lektorina. Omandanud Sorbonne'is filosoofiadoktori kraadi, siirdus ta 1946. aastal Ameerikasse, kus oli lowa ülikoolis eelkõige prantsuse keele ja kirjanduse õppejõuks, aastast 1956 professor. ${ }^{1}$ Teise Nõukogude okupatsiooni ajal said Eestisse jäänud lähedased temaga kirja teel suhelda alles 1956. aasta lõpul. Avalikkuse ette jõudis Aspeli elu ja töö 1960. aastate lõpust peale ainult mõne tema tähtpäevaga või publikatsiooniga seotud lühiartikli kaudu. Peaaegu kogu tema Eesti Vabariigi ajal tehtud töö tulemustele oli takistatud juurdepääs nende väljaannete sulgemisega erifondi, kõnelemata eesti pagulastrükistest. Nõukogude süsteemi murenemisega 1980. aastate teisel poolel hakkas vabamaks muutuma ka võimu kontrollitav inforuum. See andis võimaluse ka seni keelatud või tagaplaanile surutud autorite ja nende loomingu käsitlemiseks trükisõnas.

1980. aastate teisest poolest on Aleksander Aspeli kirjutistest ja tõlgetest kodumaal kõigepealt ajakirjas Vikerkaar uuesti avaldatud 1959. aastal Rootsis ajakirjas Mana trükitud "Sürrealism ja Ilmar Laabani „Rroosi Selaviste”" koos järelmärkusega autori kohta (Aspel 1989) ning ajakirjas Akadeemia taasüllitatud 1940. aastal üliõpilasseltsi Veljesto koguteoses „Võim ja vaim” ilmunud essee „Õnn olla väike” (Aspel 1999). ${ }^{2}$ Kõige olulisema temaga seotud väljaandena ilmus 2000. aastal Tartu kirjastuse IImamaa Eesti vaimuelu jäädavaid tekste koondavas „Eesti mõtteloo” sarjas Aspeli kirjutiste mahukas valimik „Kirjad Pariisist” (Aspel 2000), mida raamivad selle koostaja kirjandusteadlase Külliki Vulfi (Kuusk) sissejuhatus ja järelsõna. ${ }^{3}$ Teose ilmumisele pööras tähelepanu neli kriitikut (vt Kalda 2001, Maiste 2000, Tamm 2000a; Kull 2000, vt ka Kull 2005: 370-371). 2004. aastal trükiti Heiti Talviku luuletusi, arvustusi, esseid ja kirju koondavas kogumikus „Legendaarne” katkend Aspeli 1938. aastal ilmunud arvustusest luulevalimiku „Arbujad” kohta (Aspel 2004a) ning tema 1958. aastal ajakirjas Mana Rootsis ilmunud artikkel „Heiti Talviku isiksus ja luule” (Aspel

1 Eestis ilmunud varasemaist käsitlusist vt nt Siirak 1968, Kalda 1983 ja Kaks kirja... 1984; paguluses ilmunuist Oras 1958, Rannit 1958, Puhvel 1973 (eesti k Puhvel 2007), Kangro 1985.

2 Sellest on omakorda tõukunud kirjandusteadlase ja kriitiku Sirje Kiini essee väikerahvaste võimalustest „Õnn olla väike" (Kiin 2000, 2003).

3 Raamatu sisukorda ja nimeregistrit vt http://ilmamaa.ee/files/pdfs/2000/Aspel\%20luh.pdf (15.12.2011). 
2004b). Viimasel ajal on Aspeli Eesti Vabariigi aegseid kirjutisi taasavaldatud ka pidevalt täieneval veebilehel „Sõjaeelse Eesti esseistika ja kirjanduskriitika”. ${ }^{4}$

Kommenteeritud katkendi Aleksander Aspeli tõlgitud Maurice Maeterlincki teosest „Tarkus ja saatus” avaldas 1987. aastal ajalehes Põllumajanduse Akadeemia Aare Kasemets (Maeterlinck 1987). 1988. aastal ilmunud Antatole France'i kogumikus „Novellid. Esseed. Kõned” avaldati redigeerituna Aspeli 1938. aasta tõlkevalikus „Valik prantsuse esseid” leidunud „Epikurose aed” (France 1988). 1990. aastal ilmus ajakirjas Vikerkaar taas Aspeli tõlge Paul Valéry esseest „Vaimu kriisist”, mis esimest korda oli trükitud 1938. aastal ajakirjas Looming (Valéry 1990) ${ }^{5}$. Iseseisvuse taastanud Eesti Vabariigi algusaastail on osalt ärilistel eesmärkidel uuesti trükitud ka neli Aspeli varem tõlgitud teost: Curt Thomalla „Teed tervisele" (Thomalla 1991, varasemad trükid 1932 ja 1940 Tartus), Maurice Maeterlincki essee „Tarkus ja saatus” (Maeterlinck 1993; tôlge on varem ilmunud 1936. aastal Tartus ja 1955. aastal Torontos) koos Aspeli eessõnaga; André Maurois' „Kunst elada” (Maurois 1994, tõlke esmatrükk 1940 Tartus) ning Jules Verne'i „Lõuna-Aafrika savannides" (Verne 1995, tõlke esmatrükk 1934 Tartus). Maeterlincki ja Maurois' raamatute uustrükke on ajalehes Postimees tutvustanud kirjanduskriitik Aivar Kull (Kull 1993, ka Kull 2005: 7-9; Kull 1995, ka Kull 2005: 46-48).

Peale juba mainitud Aspeliga seotud kirjutiste ilmus 1992. aastal ajakirjas Akadeemia läbi nelja numbri Mart Orava artikkel „Algus: Sissejuhatus Aleksander Aspelisse. I” (Orav 1992), mille aluseks oli 1986. aastal Tartu Kirjanduse Majas peetud ettekanne (vt Pruuli 1986). Artiklis püüti kogu tollal ligipääsetava trüki- ja allikainese põhjal (näiteks ei olnud kasutada tema tütre valdusse jäänud materjale peale nooruspäeviku, kõnelemata paguluses moodustunud arhiivist) ning Aspeli eakaaslastega suhtlemisel saadud lisateabe toel esitada Aspeli elukäiku kuni Pariisi edasi õppima siirdumiseni 1938. aastal. Artikli lisana „Soovin inimestele lihtsat rõõmu" avaldati katkendeid Aspeli nooruspäevikust 1921-1929; publikatsioonis tuli eelkõige tütre soovil, aga ka ajakirja peatoimetaja soovimatuse tõttu esile tuua nooruki väidetavalt lapselikke hingeheitlusi piirduda otsese üld- ning isikuajaloolise teabega

\footnotetext{
4 Vt autorinime otsinguga aadressilt http://www.kirjandusarhiiv.net: „Puhas luule” (1935), „Teose analüüs prantsuse kirjandusõpetuses” (1935), „Fr. Tuglas stilistina” (1936), „Paul Bourget” (1936), „Lähtekohti Kreutzwaldi stiili iseloomustamiseks” (1937), „Jean Giraudoux dramaatika” (1937), „Eesti luule 1937. aastal” (1938), „Esseest” (1938), „Eluläheduse vool prantsuse kirjanduses” (1939), „Romaan ja kirjaniku mõttesüsteem” (1939), „Pariisi teater sõja eelõhtul” (1939); samuti „Sissejuhatus kunstivooludesse” ja „Antiikkunst” Aspeli teosest „Sissejuhatus kunstivooludesse” (1933) ning „Ladina pärand”, „Katoliiklik Prantsusmaa (keskaeg)”, „Suur sajand (Versailles)” tema raamatust „Prantsusmaa ja Euroopa” (1935). Samas on digiteeritud ka Johannes Semperi 1939. aastal ajakirjas Looming ilmunud arvustus Aspeli koostatud ja tõlgitud valimiku „Valik prantsuse esseid” kohta (1938).
}

5 Digiteerituna vt - http://www.kirjandusarhiiv.net/?p=358, tôlkija nimeta. 
aastaist 1928-1929. ${ }^{6}$ Artiklile pidid ilmuma järjed Aspeli Pariisi- ja Ameerika-aastaist ning tema valminud ning Iõpetamata või idee tasandile jäänud töödest. Nende jätkulugude puudumise tõttu esitas 1998. aastal sisulise järje Aspeli eluloole ajaloolane Marek Tamm artiklis "Pariis - lowa City: Aleksander Aspeli võõrsiloleku aastad (1938-1975)" (Tamm 1998), milles põhiallikaks on Aspeli kirjavahetus USAs paguluses elanud eesti kirjandusteadlase, kriitiku ja tõlkija Ants Orasega. 2000. aastal avaldasid Aspeli kohta kaks artiklit noored kirjandusteadlased: Jaan Rapp „Aleksander Aspeli paindlikkus ja paindumatus” (Rapp 2000) ning Külliki Vulf „Aleksander Aspel kirjanduslikul orbiidil” (Vulf 2000). ${ }^{7}$ 2001. aastal andis taas Marek Tamm ülevaate Aspeli eesti kirjanduse tutvustustest Teise maailmasõja aegses Prantsuse kultuuriajalehes Comœdia ning A. H. Tammsaare romaaniepopöa "Tõde ja õigus” avaldamisest prantsuse keeles (Tamm 2001). ${ }^{8}$ Aspeli kolm artiklit nimetatud ajalehes käsitlevad eesti uuemat luulet, Balti riikide kultuurielu ja A. H. Tammsaare loomingut. See oli nende artiklite esimene sisuline tutvustus eesti keeles. 2007. aastal avaldati eestikeelses tõlkes California Los Angelese ülikooli klassikaliste keelte ja indoeuroopa võrdleva keeleteaduse professori Jaan Puhveli artikkel „Neli kirjanduskriitika suurkuju 20. sajandi Eestis”, mis inglise keeles oli ilmunud 1973. aastal Oklahoma ülikooli kirjandusajakirjas Books Abroad (Puhvel 1973, 2007) ja kus Aleksander Aspel on asetatud Friedebert Tuglase, Johannes Semperi ja Ants Orase kõrvale. Seni viimaseks Aspeliga seotud käsitluseks on kirjandusteadlase Sirje Kiini värvikad reisimärkmed külaskäigust Paulène Aspeli (sünd. 1920) ${ }^{9}$ juurde lowas 2006. aasta juunis (Kiin 2011: 166-168). Heli- ja videointervjuud on autor lubanud anda Eesti Kirjandusmuuseumisse Tartus. Saame teada, et Aleksander Aspeli lesk on otsustanud Aspeli arhiivi ja suure raamatukogu pärast oma surma tervikuna pärandada lowa ülikoolile. „Põneva daami” kinnitusel olevat ta kõik eestlaste kirjad Aspelile andnud juba Kirjandusmuuseumisse Tartus, mida Kiin küll usutavaks ei pea (vt ka siin allpool). Ka hankis Sirje Kiin endale 2007. aastal kserokoopia Aspeli isikutoimikust sealse ülikooli arhiivis, milles

6 Praeguseks on Aspeli käsikirjaline päevik jõudnud Eesti Kirjandusmuuseumi kultuuriloolisesse arhiivi (EKLA, reg 2007/132).

7 Mõlema artikli aluseks on 18.-19. juunil 1999. aastal Kirjandusmuuseumi VIII Nüpli kevadkoolis „Muutuste mehhanismid" peetud ettekanded (vt teesid: Kirjandusmuuseumi... 1999).

8 Artikli aluseks on 23. veebruaril 2001 Tartus kollokviumil „Romaani kirjanduse retseptsioonist ja tõlkimisest Eestis. In memoriam Aita Kurfeldt" peetud ettekanne.

9 Vt elulooandmeid nt: http://melvyl.worldcat.org/title/paulene-violette-aspel/oclc/4780025776\&referer=brief results (15.12.2011). Tal on kasutütar Amandine (Aspel) Mothershed, kelle lapsendas pärast Aleksander Aspeli surma. Vt http://www.purposefulharmony.com/about-amandine.html (15.12.2011); https://www.facebook.com/ AmandineMothershed (15.15.2011). 
"midagi eriti üllatavat ei olnud, kuid üht-teist asjalikku siiski” (Kiin 2011: 167). ${ }^{10}$ Ühtlasi on Kiin lubanud sellest külaskäigust tulevikus pikemalt kirjutada.

Aspeli kohta iseseisvuse taastanud Eesti teatmeteoseis ilmunut ja muude kirjutiste osana avaldatut (sh nt Vikipeedias) siin ammendavalt esile ei saa tuua, ehkki sellist materjali võib vahel leida ootamatuistki kohtadest, nagu näiteks geograaf Ott Kursi raamatust (2009). Aspeli elulugu on pikemalt esitatud ka tema kodukooli, Tallinna Jakob Westholmi gümnaasiumi õpetajate ja õpilaste biograafiaid esitavas teoses (Per aspera... 1999: 25-27). Temast on lühemalt kirjutanud näiteks Marek Tamm kirjutises Gaston Bachelard'i „Ruumipoeetika” eestikeelse tõlke ilmumise puhul (Tamm 2000b), kirjandusteadlane Jüri Talvet ülevaates maailmakirjanduse teenekaist vahendajaist eesti keelde (Talvet 2005), kirjandus- ja keeleteadlane Tiit Hennoste tekstikeskse kirjanduskäsitluse vaatlusest Eesti Vabariigis (Hennoste 2007) ning eesti kirjanduse uurimisest USAs (Hennoste 2010a, 2010b). Aspelit on korduvalt mainitud Oklahoma ülikooli kirjandusajakirja Books Abroad / World Literature Today eestlasest toimetaja Ivar Ivaski päevikus, millest väike osa aastate 1964-1992 kohta on ka ilmunud (Ivask 2007); mahuka päeviku originaal on Ivaski lese valduses Riias. Lüürilise vahepalana võib veel lisada, et Aspel on jõudnud ka 1980. aastate algul tema üliõpilasseltsikaaslase Helmut Tarandi kirjutatud luuletusse „"**Mu ohver on vastu võetud”, mis avaldati alles 2011. aastal (Tarand 2011: 393-394): „Aastat kolmkümmend / Kristuse sündimise suunas / oli meil kokkupuude / André Semperi stiilistruktuuriga, / siis, kui Aspel oli kodu ega mõelnudki sellest, / et lowas neegritele prantsuse keelt lugeda." ${ }^{11}$ 1980. aastate keskpaigast peale ilmunud kirjutiste ülevaate lõpuks nimetame lisaks mõne Aspeli kirja avaldamist kogumikus „Kirjad Pariisist”: elust sõja lõpuaja Pariisis informeeriv kiri Eesti diplomaadile Kaarel Robert Pustale 14. maist 1945 (Aspel 2000: 503-506) ning kaks kirja Ants Orasele elust Ameerikas ja käsilolevatest töödest 14. veebruarist 1959 ja 2. detsembrist 1965 (Aspel 2000: 507-511, 512-514).

10 Sirje Kiini kirjavahetusest 2007. aastal lowa ülikooli pearaamatukogu arhiiviga (Main Library Special Collections Department) selgub, et Aleksander Aspeli teaduskonnatoimikus on u 75 dokumenti, sh kirjavahetust, ajaleheväljalõikeid, nekroloog, artikleid, tema lindistatud prantsuse keelematerjali masinakirjas nimistu, dokumente õppetöö kohta ning karp kaheteistkümne Aspeli publikatsiooniga ja kirjutistega tema kohta (Sirje Kiini erakirjavahetus autoriga).

11 Tükituna ekslikult „....André Sauperi...”. Tartu ülikooli magistritöös (1928) käsitles André Gide'i stiili struktuuri Johannes Semper, luuletuses on ilmselt tegu Tarandi nimemänguga. Isikulise asesõna meil taga on neis värssides Helmut Tarand ja kirjandusteadlane Mart Lepik. 
Milliseid arhiivimaterjale on aga võimalik leida Aleksander Aspeli elust ja tegevusest Teise maailmasõja lõpuaastail ja pärast sõda? ${ }^{12}$

Eesti Riigiarhiivis Tallinnas leidub Tartu ringkonnakohtu tsiviilasja kohtutoimik Helmi Aspeli lahutuse kohta (3.3.-27.6.1944); Eesti Peakonsulaadi New Yorgis fondis kirjavahetus Aleksander Aspeliga, sisaldades ka fotosid ja ajaleheväljalõikeid (14.5.1945-11.6.1958, 12.6.1968); diplomaadi Kaarel Robert Pusta isikufondis on peaaegu viiskümmend nende vastastikust kirja (1945 - 1950. aastate algus) ${ }^{13}$.

Eesti Ajalooarhiivis Tartus leidub Teise maailmasõja ajast pärinevaid kirju jm dokumente Aspeli stipendiaaditoimikuis. Samas asub Tartu Riikliku Notariaalkontori isikute teadmata äraolijaiks tunnistamise kohta käiv toimik Aleksander Aspelist (12.4.-14.4.1945), siin on hoiul ka kolm Helmi Vaganay (end Aspel) hilisema elujärguga seotud toimikut: Tartu ajalehe Edasi toimetuse isiklik toimik tema kohta (1956), ENSV Riikliku Ajaloo Keskarhiivi töötaja isiklik toimik (1955-1956) ning Tartu Riikliku Notariaalkontori pärimistoimik (1990).

Tartu Ülikooli Raamatukogu käsikirjade kogus leidub üks Aspeli sõbra ja üliõpilasseltsikaaslase Aleksander Kaelase kirja koopia Aleksander Aspelile Rootsist (21.2.1946) ning seitse Aspeli kirja Kaelasele (29.3.-25.12.1946).

Eesti Rahvusraamatukogus Tallinnas säilitatavate isikuarhiivide hulgas on ka kirjandusteadlase ja kriitiku Erna Siiraku oma (f 13), kus leidub Aleksander Aspeli ema Alma Aspeli kirju Erna Siirakule; Aleksander Aspeli ja Roman Jakobsoni pühenduste valguskoopiad Erna Siirakule Aspeli koostatud prantsuse luule antoloogia tiitellehel ja Jakobsoni artikli „Poesie der Grammatik und Grammatik der Poesie" esilelehel koos Yale'i ülikoolis töötanud eesti luuletaja ning kirjandus- ja kunstiteadlase Aleksis Ranniti kommentaaride ja kaaskirjadega (1967-1968); Aspeli artikleid Aleksis Rannitist Erna Siirakule adresseeritud märkuste ja kommentaaridega; masinakirjakoopia Erna Siiraku artiklist „Ruumi ja aja kaugusest Aleksander Aspelile mõeldes" (1968) ning Paulène Aspeli kaks tõlget Marie Underi luulest prantsuse keelde koos Aleksis Ranniti kommentaaridega (1970-1971).

\footnotetext{
12 Täpsed allikaviited leiduvad ülevaate Iõpus allikate loetelus. Eesti Arhiivi Ühendriikides Lakewoodis (http://eausa.balther.net/index.php?id=10410 (15.12.2011)) ja sealt Minnesota Ülikooli Immigratsiooni Ajaloo Uurimiskeskusele (http://www.ihrc.umn.edu/research/vitrage/all/em/ihrc97.html (15.12.2011)) üle antud arhiivifondide üldistest kirjeldustest ei õnnestunud Aspeli nime leida, kuigi nii mõneski fondis tundub temaga seotud arhiiviainese leidumine võimalik. Väliseesti arhiivkogude koondtabelit vt http://www.balther.net/valiseestiarhiivikogude-koondtabel/ (15.12.2011), kust on näha ka näiteks Eesti Kultuuriloolises Arhiivis korrastamisel olevad fondid. Mari Nõmmela on osutanud Tartus elanud kunstiajaloolase Voldemar Vaga ja Aleksander Aspeli kirjavahetusele aastaist 1958-1960, täpsustamata nende kirjade asukohta (vt Nõmmela 2008: 151).
}

13 Pusta arhiivi teine osa on 1964. aastast Stanfordi ülikooli juures asuvas Hoover Institution'is, fond on kirjeldatud aga ainult säilituskarpide tasandini. Vt http://cdn.calisphere.org/data/13030/36/kt996nf536/files/ kt996nf536.pdf (15.12.2011). 
Rootsi Riigiarhiivi deponeeritud Balti Arhiivis Stockhomis leidub eesti poliitiku August Rei arhiivimaterjalide hulgas kirjavahetust Aleksander Aspeliga aastaist 1946-1955 ja 1958; kirjaniku ja üliõpilasseltsikaaslase Karl Ristikivi kirjavahetuse hulgas kirjavahetust Aspeliga ning poliitik Aleksander Warma materjalide hulgas kirjavahetust temaga (Aspeli kiri 1950, Warma ja Aspeli kummagi kaks kirja 1955).

Eesti Kirjandusmuuseumi kultuuriloolises arhiivis Tartus on järgmised Aspeli pagulasaja kirjavahetused: keeleteadlase Johannes Aaviku üks kiri Aleksander Aspelile (1958); kolmkümmend kuus kirja kirjanikele Artur Adsonile ja Marie Underile Rootsi (1946-1974, d-ta), sh Paulène Aspeli prantsuskeelne kiri Marie Underile 1958 ja UNESCO (Milton Rosenthal) kiri Aspelile Underi luule tõlgete kohta 1964 ning katke Aspeli kirjast Aleksis Rannitile 24.10.1962; kolm kirja Adsonile (resp. Eesti PEN-klubile; 1949-1956) ja Artur Adsoni kaks kirja Aspelile (1964-1965); Aspeli kaks kirja luuletaja Betti Alverile (1966-1972); kolm kirja kirjandus- ja rahvaluuleteadlasele August Annistile kodumaal (1939-1966); kakskümmend viis kirja kirjanik Bernard Kangrole Rootsi (1949-1973, d-ta); üks kiri ajaloolasele ja üliõpilasseltsikaaslasele Eerik Laiule Rootsi (1946); kakskümmend kolm kirja kunstnik Karin Lutsule Rootsi (1950-1974, d-ta); üks kiri Bernhard Mäelole Rootsi (1956) ja Mäelo üks kiri Aspelile (1956); Aspeli üks kiri kirjanik August Mälgule Rootsi (1950); viis kirja tõlkijale Ott Ojamaale Eestisse (1972-1975) ja Ojamaa neli kirja Aspelile (1971-1975)14; Aspeli kaks kirja Ants Orasele (1943-1943) ning Aleksander ja Paulène Aspeli nelikümmend neli kirja Orasele (1950-1974, d-ta); Aspeli üks kiri kirjandusteadlasele Rudolf Põldmäele kodumaal (1966), milles leidub ka Aspeli eluloolisi andmeid pagulasajast; kirjad Aleksis Rannitile (1949-1960; sh elulugu 1958); seitseteist kirja keeleteadlasele Andrus Saarestele Rootsi (1945-1962, d-ta), sh soovituskiri Marie Underi luuletuste tõlkimiseks (1962); üks kiri kirjandusteadlasele ja kirjanikule Herbert Salule Rootsi (1974); kaheksa kirja kirjandusteadlasele ja luuletajale Gustav Suitsule (1943-1949) ja Suitsu üks kiri Aspelile (d-ta); osaline koopia Aspeli kirjast tundmatule (1958), milles leidub ülevaade tema elust sõja-aastail ja hiljem; kaks kirja kirjanik Asta Willmannile USAs (1949-1974); Rootsis tegutsenud Eesti Kirjanike Kooperatiivi (Bernard Kangro) ja Aspeli neli kirja (1950-1950) ${ }^{15}$. Samas säilivad ka ema Alma Aspeli neli kirja poliitikule ja kirjandusteadlasele Nigol Andresenile Tallinnasse (1966) ning Alma Aspeli kakskümmend üheksa kirja Mart Lepikule ja Betti Alverile Tartus (1957-1968, d-ta), milles leidub rikkalikult teavet ka poja elu ning tegevuse kohta.

14 Nendes kirjades on keskseks Aspeli tehtud Molière'i „Ebahaige” tõlke (1936) uustrükk, mis ilmuski 1974. aastal kodumaal (Molière 1974). Varasema tõlke alusel oli muide näidendit Eesti NSVs lavastatud 1945. ja 1952. aastal.

15 Kirjade hulgas Kangrole ega Eesti Kirjanike Kooperatiivile ei leidu Kirjandusliku Orbiidi kohta käivaid Aspeli kahte kirja 20. ja 29. septembrist 1962, mis Bernard Kangro on trükis avaldanud (Kangro 1985). Artikli Orav 1992 kirjutamisel olid kasutada nende Bernard Kangrolt saadud kserokoopiad. 
Eesti Kultuuriloolises Arhiivis on korrastatuna tallel ka mõned muud Aspeli pagulasajaga seotud materjalid: tema artikkel „Ants Oras au coeur de son temps” (Aspel 1965) pühendusega Ants Orasele; kaks autobiograafiat Ants Orase fondis (1958); Gustav Suitsu luuletuse tõlge „Sous les trembles frissonnants” („Värisevate haabade all”) Aspelilt (1950); Eesti Kirjanike Kooperatiivi kogutud ajaleheväljalõiked Aspeli kohta ning Ants Orase artikli „Tervituseks Aleksander Aspelile” käsikiri (vt Oras 1958). Seal leidub ka ka Paulène Aspeli tõlkeid Marie Underi luuletustest prantsuse keelde.

Sellega Eestis asuv Aleksander Aspeliga seotud arhiiviaines õnneks ei ammendu: Eesti Kultuuriloolise Arhiivi seni veel korrastamata materjali hulgas on nüüdseks ka tema tütre Rutt Leisi (1932-2006) valduses olnud kirju, dokumente ja fotosid ning Tartusse on jõudnud mõned kaustad Aspeli koduarhiivist lowas.

Nimelt tuli 2007. aastal ühes Tartu antikvariaadis müüki Aleksander Aspelile kirjutatud pühendustega trükiseid, mis pärinesid tema tütre surma järel Tartus likvideeritavast kodust. Tänu antikvaar Jana Loodi vahendusele õnnestus seal veel leiduvad kirjad, dokumendid ja fotod kokku koguda ning need Eesti Kultuurkapitali toetusega Eesti Kultuuriloolisele Arhiivile omandada (EKLA, reg 2007/132). Sisult ei ole see Aleksander Aspeli enda koduarhiiv, mis ilmselt keeruliste aegade ja inimsuhete tõttu pole säilinud, vaid eelkõige tema ema, osalt ka esimese abikaasa Helmi ning tütre valduses olnud ja näiteks kirjavahetusi vaadates ainult osaliselt säilinud materjal, kuid sellisenagi ülimalt väärtuslik. Nagu öeldud, on need ja lowast pärit säilikud praegu veel korrastamata ning seega ei kirjeldata neid siin ammendavalt ja Iõplikult. Otseselt Aleksander Aspeliga seotud ainesest leidub Tartu-materjali hulgas tema kirju emale (1928-1929, 1935) ning koos emaga ka tütar Rutile ja tütrepoegadele (19601962, 1964, 1966), kirjad abikaasa Helmile (1929, 1943-1944) ja tütar Rutile (1934-1935, 1943, 1957, 1966, 1968-1970, 1973), kirjad tütrepoegadele Andrusele ja Tiidule (mõlemad 1968), varasemast kirjamustand Nigol Andresenile (1929). Säilinud on üks ema kiri (1930) ning mustand Ruti ja Andruse kirjast (1961?), varasemast ajast on säilinud Aspeli eakaaslasest noorsotsialisti Elmar Habenichtsi (1927) ja Helmi Aspeli teise abikaasa, Tartu ülikooli prantsuse filoloogia õppejõu Léon Vaganay kirjad (1934). Leidub ka paar Aleksander Aspeliga seotud dokumenti (nimekaart, abielutunnistus (1929), abikaasa lahutusetaotlus (1945) jm), samuti ajakirjas Akadeemia 1992. aastal lühendatult avaldatud nooruspäeviku originaal. Hingesööbivad on emaarmastusest ja ahastavast igatsusest poja järele küllastatud luuletused. On nii Müntide (emapoolse suguvõsa), Aspelite, Preemide (abikaasa suguvõsa) kui ka Léon Vaganayga seotud dokumente ja kirju, mis on osalt pärit juba 20. sajandi esimesest kümnendist. Mitu väga väärtuslikku albumit ja lahtised fotod hõlmavad ajajärku tsaariajast kuni 1970. aastateni, kattes ühtlasi Aleksander Aspeli enda elukäigu. Ema on enamikule fotodele lisanud ka neil puuduva legendi.

2004. aastal külastas Aleksander Aspeli leske lowas tollane Eesti Kultuuriloolise Arhiivi juhataja Piret Noorhani, kes nii nagu Sirje Kiingi paar aastat hiljem võis pilku heita Aspelite 
kodumaja õues arhiiviga täidetud suvemajja. Noorhani sai Tartusse toimetamiseks kaasa mõne põhiliselt eestlastega seotud materjali sisaldava juhusliku kausta, mille lesk oli välja otsinud. ${ }^{16}$ Selle materjali hulgas (reg 2004/82) leidub näiteks järgmiste saatjate kirju: Artur Adson, Marie Under või mõlemad koos (1962-1964, 1966), F. Debysen (1946), Ewald (ja Mary) Ernesaks (1968), Hellar Grabbi (1966, 1968-1969), A. Ilves Henno Jänese ülesandel (1968), Ivar Ivask (1964, 1966-1970), Ants Oras (1948), Aleksis Rannit (1966-1969; sh Erna Siiraku kiri Rannitile (1966), milles on juttu Aspelist), Albert Saareste (1961), Hilja ja Karl Saaret (1974, 1975), Tiina Vedro (1967). Aleksander Aspelilt endalt on siinse ülevaate Iõpus avaldatud Marie Underile saadetud kirja jaoks tehtud mustandmärkmed (1958). Leidub (eriti ajakirjas Books Abroad) ilmunud ingliskeelsete artiklite ja arvustuste käsikirju, eestikeelse ettekande tekst Ivar Ivaski kohta 1966, ajakirjas Mana ilmunud Albert Camus' kohta käiva artikli käsikiri, mustandmärkmeid Underist jm. Orase juubelikogumiku jaoks kirjutatud artiklist „Au coeur...” on kaks koopiat ja käsikiri (1963), jm. 1957. aastast on pärit ärakirjutus lindilt Aspeli vestlusest Gaston Bachelard'iga, paberite hulgas leidub Paulène Aspeli luuletus (2004) ja koopia tema kirjast Külliki Vulfile Tartusse (2002). Üksikuid dokumente on ka Aspeli õppetöö kohta lowa ülikoolis. ${ }^{17}$ Eraldi mapi moodustavad ligi seitsekümmend kaastundekirja Paulène Aspelile abikaasa surma puhul (eestlastest nende hulgas näiteks Karin Luts-Arumaa ja Peeter Arumaa, Allin W. Dakin, Mary Ernesaks, Paul Laan, Liivi ja Ants Oras, Jaan Puhvel, Leonhard Raukas, Hildegard ja Evald Rink, Karl Saaret, täditütar Agnes Terras, Tom ja Lee Usman, Asta Willmann-Linnolt).

Nagu öeldud, on see vaid väga väike osa lowas leiduvast Aspelite arhiivist, millele juurdepääs avaneb kunagi lowa ülikoolis. Seni saab Aleksander Aspeli elu ja tööd uurida ka siinses ülevaates esile toodud kasutamata allikainesele tuginedes ning näiteks üle maailma (eriti Prantsusmaale ja USAsse) laiali pillatud kirjavahetusi ja muud temaga seotud allikainest otsida ning koondada püüdes. ${ }^{18}$

Avaldame ülevaate lisana Aleksander Aspeli kirja luuletaja Marie Underile (1883-1980) Rootsi (EKLA, f 180, m 54: 5, I 7/9-7/11). ${ }^{19}$ Järgmisel aastal kohtusid nad isiklikult Saksamaal Frankfurdis Maini ääres ülemaailmsel PEN-klubide kongressil ja Aspel on sel

16 Andmed Piret Noorhane e-kirjadest autorile 8.11.2011.

17 Võõrast materjalist on nende dokumentide hulgas näiteks koopia luuletaja Paul-Eerik Rummo kirjast Eestist kirjandusteadlasele Ivar Ivaskile USAs (1968), Ants Orase Underi-tõlkeid prantsuse keelde ning Ivar Grünthali masinakirjaline luulekogu „Sonetid 1963-1964”.

18 Tänan Sirje Kiini ja Piret Noorhane nende antud informatsiooni eest.

19 Vt ka „Marie Underi eluraamat“ (Adson 1974a: 277-278), kus see on ilmunud osaliselt ja dateerimata ning paigutatud ekslikult kümmekond aastat hilisemaks. 
puhul kinnitanud oma vaimustust luuletajast ka inimesena; see sümpaatia oli vastastikune. ${ }^{20}$ Nende loomingulisi kokkupuutepunkte on kirjeldanud Artur Adson "Marie Underi eluraamatus" (Adson 1974a, Adson 1974b), samuti kirjandusteadlane Sirje Kiin oma Marie Underit käsitlevas doktoriväitekirjas (Kiin 2009).

\author{
A. Aspel \\ 331, North Capitol St. \\ IOWA CITY. IOWA. \\ U.S.A. \\ Iowa City's, 24-ndal Märtsil 1958
}

Sügavalt austatud proua Marie Under,

Palun võtke vastu oma suure juubeli päeval, mis on meie kõigi peopäevaks, selle kauge käskjala aukartliku läkituse. Kui ta pole Uue Maailma mandrist ja tervet ookeani otsesõidus ja sõnamõisteid kaotamata loodab ületada, siis küll ainult sama jõu kandel, mis kõigist maailma otsadest 27-ndaks märtsiks me rahva kõige siiramaid ja puhtamaid tundeid Teie juure sunnib. Milline õnn aga, et prof. Oras sel päeval kohal on, et me kogeluste tõde tagada, nagu ta üksi teab! ${ }^{21}$ Võime loota Ants Orasele, et ta me käskjalgade mälukaotust ja vaikusigi seletab, mitte seepärast, et Teie neid ei mõistaks, vaid et nad kõlbaksid selle vaiba kirjaks, millele Teid palume astuda, Teid, kes olete õpetanud meid kõndima nii õigel ja täielikult inimlikul sammul.

Meie kõigi ühine Marie Under, võlgneme Teile kõige olulisema sellest imelisest soojusest, mida me enne Teid tundsime ainult umbse eluvaistuna ja pidasime meeleoluks või tundelainetuseks, milles Te luule avas aga elutäiuse enda tähenduse. Juurtest tuultesasitud harjadeni, eelsünnist üle surma läve, lapsesüütusest lapsehukkaja süüni, rõõmust needuseni ja sealt uuesti lunastuseni, ajalisest tunnist kuni meid sõelana kurnava lõpmatuse aimeni olete haaranud me elu enneolematu embusega. Siitpääle pole miski inimlik meile enam võõras.

Kuid sellest soojast küllusest vahest veelgi olulisema kingina oleme pärinud Teilt veelgi imelisema kirgastuse, kus elule langevad rasked varjudki hõõguvad kaugest selendusest. Kõik mis lahus ja eraldatud on ses varjuküpses valguses ometi seotud. Eluahel on

\footnotetext{
20 Väljaspool kirjavahetusi ja trükiülevaateid on Aleksander Aspel arvustanud Marie Underi tõlkevalimikku „La Pierre ôtée du Coeur” (Aspel 1972); avaldanud 1969. aastal ajakirjas Books Abroad artikli „Marie Under's Quest of Transcendence", mis muudetuna ja täiendatuna ilmus Aleksis Ranniti eestikeelses tõlkes 1974. aastal Rootsis (Aspel 1974a). 1974. aastal ilmus ka pealkirjaga „Marie Underi luule olemus” Aspeli ettekanne Eesti Kultuurikogu Kanadas poolt Marie Underi 90. sünnipäeva puhul korraldatud aktusel 25. märtsil 1973 Eesti Majas Torontos (Aspel 1974b).
}

21 Sel ajal Helsingis külalisprofessorina töötanud Ants Oras pidas kõne Stockholmis aktusel 30. märtsil 1958 Kontserthuseti väikeses saalis. 
katkematu ja võib olla on ta varjulised lülid kõige pidevamad. Maailmasse laialipillatud, oleme ometi koos.

Seda tõde, mida Te oma Vanemate Piiblist ${ }^{22}$ sõnade kiirgusena kogesite, kogeme nüüd Te oma sõna kiirgusena. Kui paljusid pole see valgus juba äratanud uueks sõnarõõmuks me keeles! Täna aga lubate meil veelkord, ja me läkituste kohtumises te aujärje ees nii ilmselt kogeda kui sügavalt ühendav ja põhjendav on olnud meis kõigis Teie Sõna jõud. Ükski mälestus, ükski tegu või ootus ei seo meid lähemalt kui see vaimse energia tagavara, mis meis kõigis keelena tallel ja mille ulatust Te luulesõna meile uuesti nii sundiva iluga ilmutas. See kiirgus ei piirdu aga enam põlvkondadega. Teie kaudu, Teie sõna tagatisel võime täna uuendada seda igavikuga sõlmitud kaupa, mida tundsite juba oma vanemate raamatu põhjendusvõimes.

Tänu Teile oleme jäädavamalt eestlased kui kunagi varem. Tänu Teile oleme ehtsamalt inimesed kui me muidu võinuks olla.

Me kõigi Marie Underi ema-geeniuse hõlmas hellitame aga igaüks oma isiklikku ja ainulist Marie Underit kui oma muutuvate ajede muutlikku kõlaruumi, keda pole võimalik ega õiguski lähemalt katsuda piiritleda. Armastame neid reetlikke kiiri, mis Te luulest nägematult sadades tabavad me Achillese kanda, nii nagu eluhetkete vahetud sähvatused, mis näisid ainult riivavat, käisid meist läbi ja muutsidki juba me spontaanset suunda. Selles ultra-kiirte sajus Te luulest aimame aga rohkem kui ühendavat saatust, aimame Teie sügavat vabadust, mis avab laotusi igaühe otsingule veel olematu kuid võimaliku suunas. Teie luule on olnud ja jääb sel pinnal enne kõike viljastavaks alguseks, läveks kust vaatame värisevi hingi kuid avasüli tulevikku.

\section{Sügavas austuses}

Teie

Aleksander Aspel

Prantsuse kirjanduse professor lowa riiklikus ülikoolis.

P. S. Mu prantslannast naine palub Teid oma imetluse märgina vastu võtta juurelisatud vabavärsilise tõlke Teie „Surelikust”, mille pealkirja prantsuse tänase keeletunde kohaselt ta pidi pisut muutma seda baudelaire'istades. "Manas” nr. 2 ilmunud proosatõlge oli talle esimeseks tõukeks, kuid ta on katsetanud teisigi tõlkeid Teie värssidest, mis ajajooksul võivad küpseda. Viimased "Manas” ilmunud võrratud "Somnambuul” ja „Visioon” on tal praegu käsil. Ta palub Teid ühtlasi vastu võtta oma luulekogu, mis eri-ümbrikus täna posti pandud. ${ }^{23}$

A. A. 


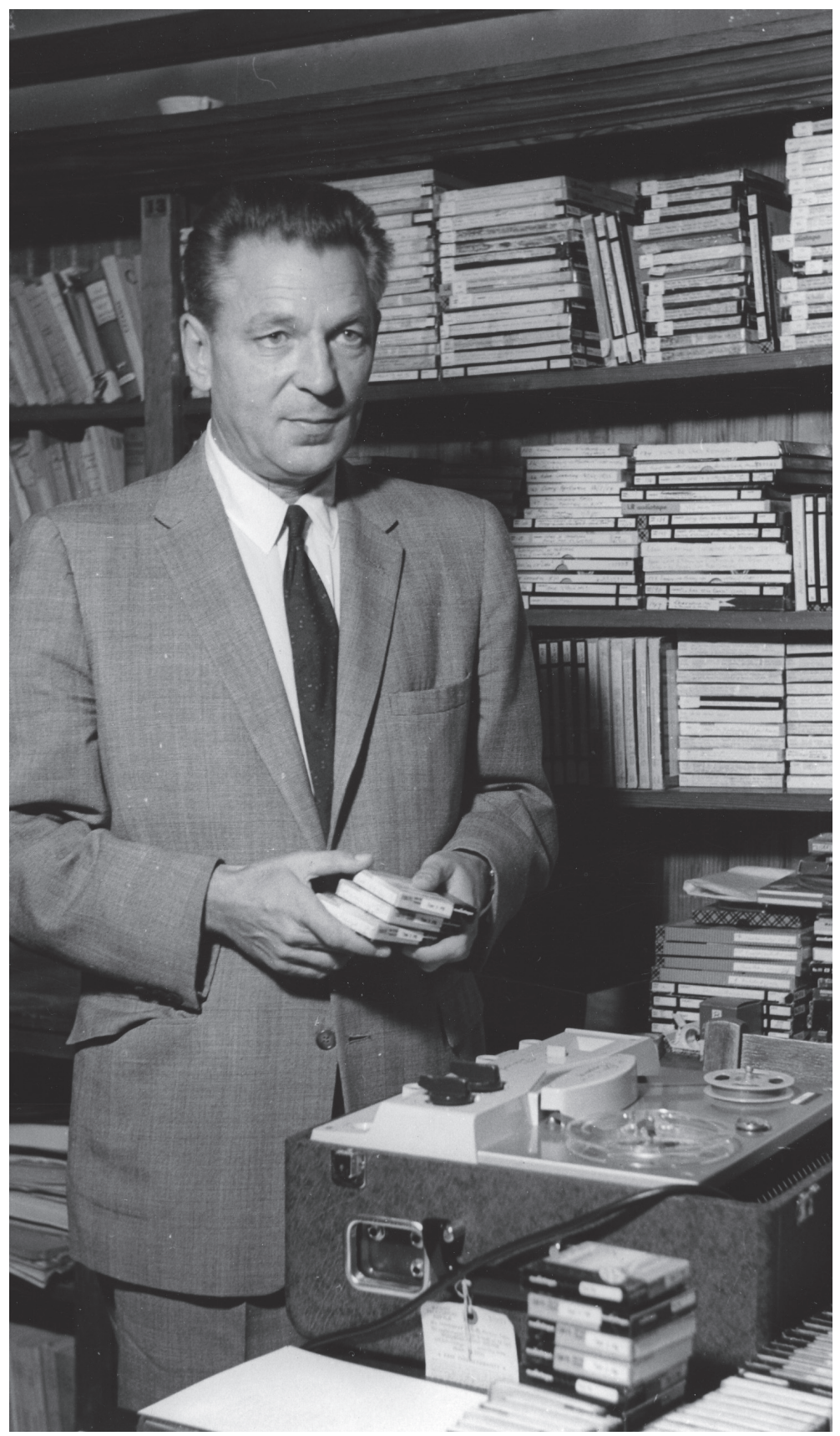

Aleksander Aspel,

lowa ülikooli

professor (Mariele).

EKLA, B-192: 151. 


\section{Kirjandus}

Adson, Artur (koost) 1974. Marie Underi eluraamat. [l kd]. Toim I. Rebane. Stockholm: Vaba Eesti.

Adson, Artur (koost) 1974b. Marie Underi eluraamat. [II kd.] Esseid. Hinnanguid. Bibliograafiat. Toim I. Rebane. Stockholm: Vaba Eesti.

Aspel, Aleksander 1965. Ants Oras au coeur de son temps. - Estonian Poetry and Language. Studies in Honor of Ants Oras. Eds. V. Kõressaar, A. Rannit. Stockholm: Vaba Eesti, Estonian Learned Society in America, Ik 32-66.

Aspel, Aleksander 1972. Marie Under. La Pierre ôtée du Coeur. - Books Abroad, Winter, Ik 144-145.

Aspel, Aleksander 1974a [1969]. Ülemeelelise tõe taotlus Marie Underi luules. TIk Aleksis Rannit. Stockholm: Vaba Eesti, Ik 131-135.

Aspel, Aleksander 1974b. Marie Underi luule olemus. Ettekanne Eesti Kultuurikogu Kanadas poolt Marie Underi 90-nda sünnipäeva puhul korraldatud kontsertaktusel, 25. märtsil 1973 Eesti Majas Torontos. - Mana, nr 41, Ik 2-7.

Aspel, Aleksander 1989 [1959]. Sürrealism ja Ilmar Laabani „Rroosi Selaviste”. - Vikerkaar, nr 3, Ik 55-64.

Aspel, Aleksander 1999 [1940]. Õnn olla väike. - Akadeemia, nr 12, Ik 2510-2515.

Aspel, Aleksander 2000. Kirjad Pariisist. (Eesti mõttelugu 31.) Koost K. Vulf. Tartu: Ilmamaa.

Aspel, Aleksander 2004a [1938]. Arbujad. [Rets. rmt: Arbujad. Valimik eesti lüürikat. Koost A. Oras. Tartu: Eesti Kirjanduse Kooperatiiv, 1938.] - Heiti Talvik, Legendaarne. Koost K. Muru, H. Runnel. Tartu: IImamaa, Ik 214.

Aspel, Aleksander 2004b [1958]. Heiti Talviku isiksus ja luule. - Heiti Talvik, Legendaarne. Koost K. Muru, H. Runnel. Tartu: IImamaa, 2004, Ik 256-283.

France, Anatole 1988 [1938]. Epikurose aed. - Anatole France, Novellid. Esseed. Kõned. Koost O. Ojamaa, tlk A. Aspel, H. Kaarde, N. Kaplinski, L.-M. Kask, H. Kolle, O. Ojamaa ja M. Riives. Tallinn: Eesti Raamat, Ik 315-325.

Hennoste, Tiit 2007. Hüpped modernismi poole II. 20. sajandi eesti kirjandusteadus Euroopa kirjandusteaduse taustal. 7. loeng: esimene hüpe teksti poole 1920.-30. aastate vahetusel. Vikerkaar, nr 3, Ik 93-106.

Hennoste, Tiit 2010a. Hüpped modernismi poole II. 20. sajandi eesti kirjandusteadus Euroopa kirjandusteaduse taustal.18. loeng. Pagulasaastad IV: kirjandusuurimine USA-s. - Vikerkaar, nr 1/2, Ik 147-157.

Hennoste, Tiit 2010b. Hüpped modernismi poole II. 20. sajandi eesti kirjandusteadus Euroopa kirjandusteaduse taustal. 19. loeng. Pagulasaastad V: poeetika ja modernism II. - Vikerkaar, $\mathrm{nr} 4 / 5$, Ik 156-168.

Ivask, Ivar 2007. Olla need, kes me oleme. Katkeid päevikutest aastatel 1964-1992. (Litteraria. Eesti kultuuriloo allikmaterjale 24.) Koost S. Olesk. Tartu: Eesti Kirjandusmuuseum.

Kaks kirja Nigol Andresenile. Komment. P. Olesk [ja M. Orav]. 1984. - Keel ja Kirjandus, nr 10, Ik 626-628.

Kalda, Maie 1983. Kirjanduse sisse minek. - Looming, nr 6, Ik 852-853.

Kalda, Maie 2001. Aspel - klassik või mitte?. - Raamatukogu, nr 3, Ik 33. 
Kangro, Bernard 1985. Aleksander Aspel, Ants Oras ja teised Kirjanduslikust Orbiidist: kirju ja mälestusi asjaosalistelt. - Tulimuld, nr 4, Ik 210-220.

Kiin, Sirje 2000. Õnn olla väike. - Postimees, 10. dets.

Kiin, Sirje 2003. Õnn olla väike. - Sirje Kiin, Kõik sõltub kultuurist. Tallinn: S. Kiin, Ik 10-12.

Kiin, Sirje 2009. Marie Under. Elu, luuletaja identiteet ja teoste vastuvõtt. Tallinn: Tänapäev.

Kiin, Sirje 2011. Kas Ameerika on olemas? Kirjad Madisonist 2005-2009. Tallinn: Tammerraamat.

Kirjandusmuuseumi VIII Nüpli kevadkool. Muutuste mehhanismid 18. ja 19. juuni 1999. Teesid. 1999. (Nüpli kevadkool 8.) [Tartu]: Eesti Kirjandusmuuseum, Eesti Kirjanduse Selts. Vt ka http://www.kirmus.ee/nypli/koolid/1999/index.html (15.12.2011).

Kull, Aivar 1993. Ratsionalistlik müstik. - Postimees, 26. mai.

Kull, Aivar 1995. Elulugudemeistri elukunst. - Postimees, 21. märts.

Kull, Aivar 2000. Aleksander Aspel kui aken Euroopasse. - Tartu: Postimees, 28. sept.

Kull, Aivar 2005. Kulli pilk. Tartu: IImamaa.

Kurs, Ott 2009. Aleksander Aspel. - Ott Kurs, Elusid ja eluruume. Tartu: IImamaa, 2009, Ik 138-139.

Maeterlinck, Maurice 1987. Tarkus ja saatus. [Katkend, komment. A. Kasemets] Põllumajanduse Akadeemia, 8., 22. ja 29. jaanuar, 25. juuni, 22. sept.

Maeterlinck, Maurice 1993 [1936, 1955]. Tarkus ja saatus. TIk A. Aspel. Tallinn: Kupar.

Maiste, Valle-Sten 2000. Aleksander Aspel. Kirjad Pariisist. - Postimees: Arter, 1. juuli.

Maurois, André 1994 [1940]. Kunst elada. TIk A. Aspel. [2., keeleliselt red tr.] Tallinn: Aed.

Molière 1974. Ebahaige. TIk A. Aspel, [värsid] A. Oras. - Molière, Näidendid. Koost O. Ojamaa. Tallinn: Eesti Raamat, Ik 719-836.

Nómmela, Mari 2008. Voldemar Vaga (1899-1999) ja Eesti kunsti ajalugu. (EKLA töid kirjandusest ja kultuuriloost 5.) Tartu: EKM Teaduskirjastus.

Oras, Ants 1958. Tervituseks Aleksander Aspelile (tema 50-nda sünnipäeva puhul). - Mana, nr 4, Ik 2-4.

Orav, Mart 1992. Sissejuhatus Aleksander Aspelisse I. I-IV. - Akadeemia, nr 8-11, Ik 1640-1672, 1822-1856, 2061-2096, 2386-2392.

Per aspera ad astra III: Jakob Westholm ja tema kool. 1999. Peatoim R. Toomsalu. Toronto-Tallinn: Jakob Westholmi Gümnaasiumi vilistlased.

Pruuli, Tiit 1986. Ainet gallofiili biograafiale. - Looming, nr 7, Ik 1002-1003.

Puhvel, Jaan 1973. Four arbiters of literature in $20^{\text {th }}$-century Estonia: Tuglas, Semper, Oras and Aspel. - Books Abroad, Vol. 47, Ik 636-642.

Puhvel, Jaan 2007 [1973]. Neli kirjanduskriitika suurkuju 20. sajandi Eestis. - Jaan Puhvel, Võõraile võõrsil. Eesti- ja soomeainelisi esseid ja arvustusi. Tartu: IImamaa, Ik 24-34.

Rannit, Aleksis 1958. Aleksander Aspeli esteetika ja humanism. - Mana, 1958, nr 4 (3), Ik 28-34. [Eraldi trükis prantsuskeelse rööpteksti ja bibliograafiaga: New York, 1958.]

Rapp, Jaan 2000. Aleksander Aspeli paindlikkus ja paindumatus. - Muutuste mehhanismid eesti kirjanduses ja kirjandusteaduses. Ettekandeid ja artikleid 1999. Koost M. Laak, S. Olesk. Tartu: Eesti Kirjandusmuuseum, Ik 122-126.

Siirak, Erna 1968. Ruumi ja aja kaugusest Aleksander Aspelile mõeldes. - Looming, nr 6, Ik 931-935. 
Talvet, Jüri 2005. Maailmakirjandus Eestis. Vahendajad: nähtavuse ja nähtamatuse arhetüübid. Jüri Talvet, Tõrjumatu äär. Tartu: IImamaa, Ik 333-370.

Tamm, Marek 1998. Pariis - lowa City: Aleksander Aspeli võõrsiloleku aastad (1938-1975). - Keel ja Kirjandus, nr 7, Ik 467-477.

Tamm, Marek 2000a. Avastamata Aspel. - Eesti Ekspress, 3. aug.

Tamm, Marek 2000b. Eesti Bachelard. - Vikerkaar, nr 5-6, Ik 166-169.

Tamm, Marek 2001. Kollaboratsionismi paradoksid. Eesti kirjandus okupeeritud Prantsusmaal (1940-1944). - Looming, nr 8, Ik 1210-1218.

Tarand, Helmut 2011. Ürglohutus. Koost, komment. M. Kuldkepp. Tallinn: Eesti Keele Sihtasutus.

Thomalla, Curt 1991 [1932, 1940]. Teed tervisele. Tervishoid, moodsad ravimisviisid ja igapäevased kehaharjutused. TIk A. Aspel. 2. tr [p.o 3. tr]. Tallinn: Roto.

Valéry, Paul 1990 [1938]. Vaimu kriisist. TIk A. Aspel. - Vikerkaar, nr 7, Ik 44-46.

Verne, Jules 1995 [1934]. Lõuna-Aafrika savannides. TIk A. Aspel. Tallinn: Kuldsulg.

Vulf, Külliki 2000. Aleksander Aspel kirjanduslikul orbiidil. - Muutuste mehhanismid eesti kirjanduses ja kirjandusteaduses. Ettekandeid ja artikleid 1999. Koost M. Laak, S. Olesk. Tartu: Eesti Kirjandusmuuseum, Ik 127-135.

\section{Käsikirjalised allikad}

\section{Balti Arhiiv (Rootsi Riigiarhiiv, Stockholm)}

August Rei kirjavahetus Aleksander Aspeliga, 1946-1955. - BA, August Rei's arkiv, kartong nr 1a, mapp 2, korrespondens A-F.

August Rei kirjavahetus Aleksander Aspeliga, 1955, 1958. - BA, August Rei's arkiv, kartong nr 2, korrespondens I, 11.

Karl Ristikivi kirjavahetus Aleksander Aspeliga, d-ta. - BA, Karl Konstantin Ristikivi arkiv, kartong nr 26, m 3, 1.

Aleksander Warma kirjavahetus Aleksander Aspeliga, 1950, 1955. - BA, Aleksander Warma's arkiv, kartong $\mathrm{nr}$ 20, korrespondens, mindre I A-I, 12.

Eesti Ajalooarhiiv (Tartu)

Ajalehe „Edasi” toimetus. Isiklik toimik Helmi Vaganay kohta, 1956. 5 I. - EAA, f V-35, n 1k, s 102.

Eesti Vabariigi Tartu Ülikooli stipendiaadi toimikud, Aleksander Aspel. - EAA, f 2100, n 2, s 43; f 2100, n 2b, s 7 .

ENSV Riiklik Ajaloo Keskarhiiv. Isiklik toimik Helmi Vaganay kohta, 16.10.1955-16.01.1966. 5 I. - EAA, f R-271, n 1k, s 629.

Tartu Riikliku Notariaalkontori toimik Aleksander Aspeli teadmata äraolijaks tunnistamise kohta, 12.04.-14.04.1945, 9 Ik. - EAA, f T-451, n 1, s 986.

Tartu Riiklik Notariaalkontor. Helmi Vaganay pärimistoimik, 04.07.1990-29.11.1990. - EAA, f T-451, n 2, s 13335. 
Eesti Kirjandusmuuseumi kultuurilooline arhiiv (EKLA, Tartu)

\section{Kirjavahetused}

Johannes Aavik, üks kiri Aleksander Aspelile, 3. juuni 1958; 1/1 I. - EKLA, f 275, m 128: 4.

Artur Adson, kaks kirja Aleksander Aspelile, 4.8.1964-2.9.1965; 2/3 I. - EKLA, f 180, m 40: 3.

Aleksander Aspel, kolmkümmend kuus kirja Artur Adsonile ja Marie Underile, 11.5.194616.5.1974, d-ta; 36/69 I, fotod. - EKLA, f 180, m 54: 5.

Aleksander Aspel, kolm kirja Artur Adsonile (Eesti PEN-klubile), 20.8.1949-9.5.1956; 3/4 I. - EKLA, f 329, m 33: 14.

Aleksander Aspel, kaks kirja Betti Alverile, 22.12.1966-28.8.1972; 2/4 I - EKLA, f 315, m 7: 13.

Aleksander Aspel, kolm kirja August Annistile, 17.12.1939-21.12.1966; 3/5 I. - EKLA, f 218, m 2: 17.

Aleksander Aspel, kakskümmend viis kirja Bernard Kangrole, 25.12.1949-18.5.1973, d-ta; 25/55 I. - EKLA, f 310, m 52: 10.

Aleksander Aspel, üks kiri Eerik Laiule, 29.3.1946; 1/1 I. - EKLA, f 375, m 119: 10.

Aleksander Aspel, kakskümmend kolm kirja Karin Lutsule, 4.4.1950-1.1.1974, d-ta; 23/24 I. EKLA, f 349, m 96: 9.

Aleksander Aspel, üks kiri Bernhard Mäelole 19.3.1956; 1/1 I. - EKLA, f 226, m 78: 16.

Aleksander Aspel, üks kiri August Mälgule, 27.8.1950; 1/1 I. - EKLA, f 338, m 1: 5.

Aleksander Aspel, viis kirja Ott Ojamaale, 28.6.1972-16.1.1975; 5/9 I. - EKLA, f 374, m 3: 16.

Aleksander Aspel, kaks kirja Ants Orasele, 15[1?].12.1943-18.12.1943; 2/3 I. - EKLA, f 237, m 52: 10.

Aleksander ja Paulène Aspel, nelikümmend neli kirja Ants Orasele, 2.9.1950-20.10.1974, d-ta; 44/64 I. - EKLA, f 237, m 8: 11.

Aleksander Aspel, üks kiri Rudolf Põldmäele, 22.2.1966; 1/1 I. - EKLA, f 375, m 13: 4.

Aleksander Aspel, kirjad Aleksis Rannitile, 16.10.1949-13.12.1960; 65 I. - EKLA, f 375, m 68: 1 (kserokoopiad Yale'i ülikooli raamatukogust).

Aleksander Aspel, seitseteist kirja Andrus Saarestele, 30.7.1945-6.1.1962, d-ta; 17/19 I. -EKLA, f 254, $m$ 18: 11 .

Aleksander Aspel, üks kiri Herbert Salule, 1974 (pt); 1/ 2 I. - EKLA, f 378, m 8: 16.

Aleksander Aspel, kaheksa kirja Gustav Suitsule, 30.12.1943-27.12.1949; 8/21 I. - EKLA, f 333, m 7: 14 .

Aleksander Aspel, ärakirja katkend kirjast tundmatule, 6.12.1958; 4 I. - EKLA, f 315, m 193: 4.

Aleksander Aspel, kaks kirja Asta Willmannile, 24.7.1949-7.4.1974; 2/2 I. - EKLA, f 329, m 31: 22.

Alma Aspel, neli kirja Nigol Andresenile, 21.2.1966-6.8.1966; 4/8 I. - EKLA, f 311, m 7: 10.

Alma Aspel, kakskümmend üheksa kirja Mart Lepikule ja Betti Alverile, 18.9.1957-13.6.1968, d-ta; 29/84 + 4 fotot. - EKLA, 315, m 158: 10.

Eesti Kirjanike Kooperatiiv, kirjavahetus Aleksander Aspeliga, 1.3.1950-23.7.1950; 4/5 I. - EKLA, f 341, m 2: 37.

Bernhard Mäelo, üks kiri Aleksander Aspelile, 18.2.1956; 1/1 I. - EKLA, f 226, m 68: 13. 
Gustav Suits, üks kiri Aleksander Aspelile, d-ta, 1/ 2 I. - EKLA, f 333, m 1: 3.

Ott Ojamaa, neli kirja Aleksander Aspelile, 1.12.1971-11.4.1975; 4/4 I. - EKLA, f 374, 1: 4.

Muu materjal

Aleksander Aspel. Artikkel „Ants Oras au coeur de son temps” (pühendusega Ants Orasele), 22 I. EKLA, f 237, m 51: 8.

Aleksander Aspel. Autobiograafia jm andmeid, 1958, d-ta; 3 I. - EKLA, f 237, m 49: 14.

Aleksander Aspel. Gustav Suitsu luuletuse tôlge pealkirjaga „Sous les trembles frissonnants”, 1950, 1 I. - EKLA, f 333, m 148: 2.

Ants Oras. „Tervituseks Aleksander Aspelile” (käsikiri). - EKLA, f 180, m 261: 4.

Eesti Kirjanike Kooperatiiv, ajaleheväljalõiked Aleksander Aspeli kohta. - EKLA, f 341, m 440: 2.

Paulène Aspel. Marie Underi luuletuste tõlked prantsuse keelde, 8 I. - EKLA, f 180, m 231: 11.

\section{Korraldamata materjal}

[Aleksander Aspeli tütre Rutt Leisi kodust Tartus pärit kirjad, dokumendid ja fotod.] - EKLA, reg 2007/132.

[Aleksander Aspeli koduarhiivist lowas pärit kirjad, käsikirjad jm.] - EKLA, reg 2004/82.

Eesti Rahvusraamatukogu kogude osakond (Tallinn)

Aleksander Aspeli ja Roman Jakobsoni pühendused Erna Siirakule A. Aspeli prantsuse luule antoloogia tiitellehel ja R. Jakobsoni artikli „Poesie der Grammatik und Grammatik der Poesie” esimesel lehel. Valguskoopiad A. Ranniti kommentaaridega ja kaaskirjadega, 1967-1968, 3 Ik. RR, f 13, s 170 .

Alma Aspel, kirjad Erna Siirakule. - RR, f 13, s 180.

Artiklid Aleksis Rannitist (A. Aspel, H. Kompus, A. Willmann, A. Oras, A. Vihalemm jt). Fragmendid ja koopiad trükistest, masinakirjakoopiad jms A. Ranniti poolt Erna Siirakule adresseeritud märkuste ja kommentaaridega, 1956-1978, 103 Ik. - RR, f 13, s 165.

Erna Siirak, masinakirjakoopia artiklist „Aja ja ruumi kaugusest Aleksander Aspelile mõeldes”, 1968, 10 lk. - RR, f 13, s 221.

Marie Underi luule tõlkimisest prantsuse keelde; sh Paulène Aspeli kaks tõlget Aleksis Ranniti kommentaaridega, 1970-1971. - RR, f 13, s 60.

Eesti Riigiarhiiv (Tallinn)

Tartu Ringkonnakohtu toimik Helmi Aspeli abielulahutuse kohta, 3.3.-27.6.1944. - ERA, f R-975, n 1 , s 111 .

Eesti Peakonsulaadi New Yorgis kirjavahetus Aleksander Aspeliga, tema fotod ning ajaleheväljalõiked tema kohta, 14.5.1945-11.6.1958, 12.6.1968, 73 Ik. - ERA, f 1608, n 2, s 1720.24

24 Säilik on digiteeritud, kuid muudetud virtuaalse uurimissaali (VAU) kaudu piiratud juurdepääsuga materjaliks. 
Kaarel Robert Pusta kirjavahetus väliseestlastega A-Asp, sh Aleksander Aspeliga. - ERA, f 1622, n 2, s 65 (kasutatav ka virtuaalse uurimissaali VAU kaudu: http://www.ra.ee/dgs/browser.php?tid=1 73\&iid $=110702561732 \& \mathrm{lst}=2 \& \mathrm{idx}=1 \& \mathrm{img}=$ era1622_002_0000065_00001_m.png\&hash $=25$ 8f985fe3ff453510d9043d11 ef2f7b (15.12.2011)).

lowa ülikooli pearaamatukogu arhiiv (Main Library Special Collections Department, lowa) Faculty file of Alexandre Aspel. - RG99.0079.

Tartu Ülikooli Raamatukogu käsikirjakogu

Aleksander Aspel, seitse kirja Aleksander Kaelasele, 29.3.-25.12.1946, 9 I. TÜR KHO, f 151, s 144.

Aleksander Kaelas, üks kiri Aleksander Aspelile, 21.2.1946, 1 I. TÜR KHO, f 151, s 118.

Mart Orav - on lõpetanud Tartu ülikooli filoloogiateaduskonna 1982. aastal. Praegu kultuuriajakirja Akadeemia humaniora ja socialia osakonna toimetaja Tartus. 